\title{
A FUNÇÃO SIMBÓLICA E SEUS DESVIOS: DESA- FIOS IMPLICADOS NA RELAÇÃO ENTRE DESEJO, LEI E VIOLÊNCIA
}

\author{
Alba Gomes Guerra \\ Glória Carvalho
}

\begin{abstract}
On the basis of empirical data, the theme of violence is brought into discussion. Supported by Lacan's ideas as our theoretical background, the concept of the paternal fatherlike/symbolic role stands out as it interdicts the omnipotence of desire. In addition, the consequences of such an omnipotent desire, in its transgresssive nature, have been taken as implying a destructive result generated within the social realm, and returning to it on account of its totalitarian/omnipotent/immoderate character.
\end{abstract}

Key words: Psychoanalysis, violence, desire, law, language.

Pretendemos aqui refletir sobre a violência, assumindo como eixo a dialética humana que irrompe entre a ilusão de onipotência e a condição de impotência. Tendo como marco a ciência psicanalítica, consideramos relevante partir de alguns pontos do processo afetivo, por serem esses constitutivos do sujeito e responsáveis por seus desvios/transgressões no campo social.

Ao nascer, pela sua imaturidade biológica - maior que a de qualquer outro animal - o bebê depende, integralmente, do outro. Essa experiência de dependência/desproteção/fragilidade se tornaria ainda mais singular, em virtude da premência que teria o humano de dar continuidade ao seu projeto de ser, diferentemente do animal, que já nasceria pronto e detentor de uma programação instintiva que o orientaria na vida. Segundo a psicanálise, o que iria fazer face a essa indeterminação, ou seja, a essa condição de extremo desamparo, seria a possibilidade humana de se beneficiar das relações afetivas construídas. 
Caberia indagar, mesmo assim, sobre o custo dessa indeterminação com o qual apenas o ser humano e, sem escolha, teria que arcar. Indagamos, ainda, se a raiz de tal custo não estaria na possibilidade de múltiplos caminhos a seguir, permitindo, até mesmo, o confronto com o que não está presente, portanto, com o desconhecido / inesperado / imprevisível. E por que o sujeito teria essa possibilidade de se confrontar com algo, em seu estatuto de ausente? Não seria, pela sua condição de ser falante, ou ainda, de ser de linguagem, capturado/tomado pelo simbólico?

Afirmar isso por certo que implicaria em conceber o sujeito como ser de desejo, portanto, de inconsciente. É o que tentaremos discutir a seguir.

$\mathrm{Na}$ concepção psicanalítica, o inconsciente seria uma qualidade que se constituiria a partir de conteúdos omitidos da consciência (recalcados) e que permaneceriam produzindo efeitos, independentemente de um saber e de um controle por parte do sujeito. Portanto, o sujeito seria um ser submetido a um movimento ou força, ou energia, que o impulsionaria a uma busca incessante de satisfação, nunca, porém, plenamente satisfeita, por não depender, apenas, dos objetos da realidade. Diferentemente da necessidade - que teria objeto próprio e, portanto, poderia ser satisfeita o desejo, enquanto estado de falta, teria a dimensão de fantasia, daí o seu caráter inatingível. Tendo o sujeito o poder de fantasiar, quer dizer, de encenar o seu próprio desejo, tal encenação somente seria possível através dos recursos que a linguagem lhe oferece, razão pela qual seria a linguagem o que constituiria o próprio desejo. Em outras palavras, o sujeito desejaria pela sua condição de sujeito do simbólico e, também, porque não se aceitaria como incompleto, ou seja, não aceitaria o limite que a lei/ interdição imporia ao seu prazer, no sentido da realização do seu desejo. E por que a lei, necessariamente, contraria o desejo?

Diríamos que pelo caráter ilimitado/desmedido do desejo, na busca de uma satisfação inalcançável. E, ainda, porque nunca seria ele desejo de alguma coisa, mas se constituiria como um esforço para a saída de um estado de insatisfação e, assim, diferindo da necessidade, não teria objeto próprio, donde o seu caráter insaciável/desmedido. Nesse sentido, seria sempre um desejo que não se poderia circunscrever pelo quantum de fantasia de que se revestiria. Daí porque, na proposta psicanalítica, tudo o que reali- 
zamos, seriam representações imperfeitas dos objetos/coisas almejados. Nessa perspectiva, seríamos, portanto, sempre movidos a desejar, a despeito de sermos, inexoravelmente, surpreendidos por constantes desilusões/frustrações, uma vez que, reafirmamos, o desejo nada mais seria que uma força propulsora rumo ao inatingível. E de que lei/interdito se estaria falando?

Segundo o pensamento freudiano, a lei seria uma injunção, uma barra, um limite no curso do desejo. Em outras palavras, seria a força restritiva que se imporia ao ser humano, enquanto falante, face às tentativas de realizar o seu desejo, servindo-se de mediações. Tais mediações resultariam em adiamentos ou substituições no curso do movimento desejante. Vale destacar, contudo, que esse poder de interferir no curso do desejo não operaria de acordo com aquele controle que o sujeito supõe exercer sobre si mesmo e sobre os outros. Esse poder de controle resultaria, tão somente, da força interditora do simbólico, da palavra. Quando tal poder não se faz suficiente teria lugar a atuação que se convencionou designar de passagem ao ato. O referido poder de controle seria um impedimento ou obstáculo à imediata realização do desejo. Entretanto, estaria fora do domínio consciente/racional do sujeito. Seria, portanto, a lei universal ou função paterna (manifesta em qualquer expressão simbólica que, representasse a proibição da fantasia de um gozo pleno), o que daria ao sujeito a condição na e pela qual ele se constituiria, atingindo o seu estatuto de ser social, capaz de incorporar/assimilar uma gramática de direitos e deveres, bem como de se submeter, ele mesmo, a essa gramática. Por ela, o sujeito se habilitaria a construir cultura, laços afetivos e regras de convivência social, tornando-se, então, capaz de se relacionar, solidariamente, com o outro. E esse seria o solo sobre o qual se edificariam os ideais de uma cultura, portanto, os freios da violência.

\section{UM LUGAR ESTRUTURANTE DA FUNÇÃO SIMBÓLICA}

$\mathrm{Na}$ sua releitura de Freud, Lacan assume como premissa básica a afirmação de que não existiria desejo sem lei. A essa lei universal, abstrata e estruturante, designou de função paterna ou função simbólica. Seria essa função 
o que daria a condição de sujeito, ou seja, a medida do ser humano. Vale lembrar o que, nesse sentido, dissera um grande pensador grego chamado Protágoras, isto é, que o homem seria a medida das coisas porque, enquanto ser de linguagem, ele daria nome a essas coisas e assim, ao revesti-las com a palavra as faria passar do mundo da realidade para o universo simbólico, o mundo da cultura. Nesse mesmo solo, a psicanálise também teria pisado, ao considerar a dimensão simbólica como sendo a marca que singularizaria o humano em relação aos demais seres, uma vez que somente essa função permitiria ao sujeito elevar a coisa faltante à categoria de conceito. Admitimos que essa função paterna/simbólica poderia vir a ser exercida por diferentes operadores (homem ou mulher, família, outros grupos, etc.), e em circunstâncias sócio-históricas as mais diversas. Sem que pretendamos desconhecer as conseqüências que possam decorrer, em virtude das especificidades culturais, o que reafirmamos seria o inevitável lugar estruturante da função simbólica, sempre que o humano se fizer presente. A função simbólica, de algum modo, ocorreria, no sentido de ser algo que barraria a força desmedida do desejo. Caso assim não o fosse, teríamos um mundo dominado pelo prazer sem limite e, portanto, um mundo regido por um movimento destrutivo. Explicando melhor, enquanto concebido como ser de desejo, porque constituído na falta, seria o sujeito instalado numa dor e numa angústia incuráveis, resultantes de um permanente estado de falta e de uma esmagadora vivência de se saber finito, incompleto, porém, atrelado a um desejo desmedido que nunca se satisfaria. E assim, enquanto sujeito que deseja o inatingível, o impossível, o inominável, seria, também, um ser de sofrimento e que não deixaria de aspirar a uma retificação subjetiva para suportar a sua dor.

Considerando o que foi colocado até aqui, talvez não seja demais afirmar que só haveria sofrimento humano por conta do simbólico (da falta). Se esse desaparecesse desapareceria, também, segundo Lacan, a condição humana de sujeito. E se desaparecesse a condição humana de sujeito só restaria a condição animal e, assim mesmo, não realizada, porque sem a programação instintiva dos outros animais. Nesse contexto, “as coisas do mundo humano são coisas de um universo estruturado em palavras, onde a linguagem domina, onde os processos simbólicos governam, tudo" (Souza, 1988, p. 95). 
Estamos, desse modo, diante de um dos paradoxos da psicanálise, no sentido de que a lei que institui é a mesma que limita/barra o desejo. E o faz, através da linguagem. Nesse sentido, o estatuto de lei - porque instituído e exercido na e pela linguagem - seria para Lacan, legitimamente, remetido ao estatuto de um significante, quer dizer, de elementos do discurso que se deslocam continuamente e cujo sentido somente se daria na cadeia de outros significantes, os quais determinariam e representariam o próprio sujeito. Reafirmamos, pois, que a marca que diferencia o ser humano, em relação ao restante do universo, seria a linguagem - isto é, essa possibilidade que tem o sujeito de se comunicar num outro nível que não apenas o sensitivo. Ao que parece, sem linguagem/simbólico o sujeito não seria nada, repetimos, nem mesmo um animal, visto que não teria o arsenal adaptativo de que esse dispõe. Como diz Paul Henry (1992), seria a linguagem/o simbólico que permitiria ao homem a flexibilidade para livrar-se da reprodução do mesmo, do igual, o que não aconteceria na préprogramação instintiva dos animais. Somente o homem poderia, entre outras coisas, enganar e se enganar, escolher, lidar com o equívoco, com o enigma, crer naquilo que sequer entende, assumir e produzir ideais etc. Valeria insistir que somente a condição de ser falante impediria o humano da morte provocada pela reprodução do mesmo, do igual. Por exemplo, entre as abelhas, o hábito de transmitir mensagens de um determinado modo poderia fazer com que qualquer coisa que a isso se interpusesse provocasse a morte, pela quebra de um caminho pré-programado, visto que não haveria, como no humano, a escolha entre a palavra ou a morte. Isso quer dizer que não haveria a possibilidade de, pela palavra, ou seja, pelo simbólico, buscar alternativas que evitassem aquela morte, resultante da quebra de um determinismo instintivo.

\section{UM RECORTE EMPÍRICO COMO ILUSTRAÇÃO}

Para jogar um pouco de luz nessa reflexão, apelaremos, agora, ao dado empírico, resgatando um pequeno recorte da história-crime de um homem, objeto de um estudo sobre o homicídio (Guerra, 1990).

Pretendendo tornar cada vez mais visível a nossa posição de que, no mundo humano, o que se repete é sempre com diferença e que, assim, 
toda interpretação é provisória, portanto, passível de ressignificações, escolhemos como ilustração um caso/dado que já analisamos em outros momentos (Guerra 1990 e 1998), servindo-nos de outras óticas.

Com três facadas, Janino provocou morte imediata em um senhor de 64 anos, a partir de uma discussão onde, depois de chamá-lo homossexual, pôs dúvidas quanto à paternidade que esse senhor presumia ter, como fruto da relação amorosa mantida com uma jovem senhora. O crime teria acontecido, sem que a vítima tivesse qualquer reação violenta, após os insultos de Janino. As pessoas que no processo falam da vítima, a referem como "muito franzina, parecendo uma criança". Janino afirma que ela nunca lhe fez mal e que só a matou porque "foi tomado pelo demônio". Uma das testemunhas do crime informou que Janino, ao consumar o ato, ficou olhando para a vítima e, logo em seguida, pulava por cima do cadáver em movimentos que se repetiam. Janino é de origem rural, de cor negra, solteiro e analfabeto. É o segundo filho de uma família de sete irmãos. A maior parte de toda a sua vida foi vivida numa extrema pobreza, tendo passado fome por longos períodos. Sobre isto nos diz ele:

quando eu era pequeno, dinheiro eu tinha... Tinha, mas não podia pegar, porque ele desaparecia da minha mão... Devido ao problema da minha qualidade, não posso fazer nada. Leitura não entra na minha cabeça, mode o problema da minha qualidade. Quando eu for completo, posso fazer tudo que eu quero. É quando esse couro preto sair e eu ficar todo branco... Aí eu sou o dono do mundo...

O pai de Janino tem 56 anos e a mãe, 60 anos. Ele nos diz:

não me dou bem com o velho... quer dizer, eu me dava bem, ele é que não quer nada. Eu nunca o chamei de pai. Só chamo velho. Sei que ele quer sempre me matar. Aliás, tem muita gente querendo me matar, até na família. Mas, eu já disse que não adianta, porque eu sou semente e aí nasço de novo. Dizem que ele gostava de mim e deixou de gostar quando eu disse que ele não era meu pai. Eu tinha mais ou menos 6 anos. Várias vezes eu pulei nas becas dele, quando via ele agarrando nas becas de minha mãe. Aí eu ia matá-lo. Eu gostava mais de mãe. Uma vez tentei matá-la. Lembro que um dia vi mãe lavando panos de mulher sujos de sangue e aí perguntei a ela o que era aquilo e ela me respondeu: nego safado, isso é coisa que se pergunte! 
Disse-nos uma irmã de Janino:

quando ele nasceu, tinha um adivinhão lá, no sertão, que logo que olhou para ele disse que mãe ia chorar lágrimas de sangue por causa dele. Aí ele pediu a ela prá dar Janino para ele criar, mas ela não quis. Talvez o adivinhão quisesse ter ficado com ele para criar porque, sendo sábio, certamente saberia algum remédio para evitar o mal e tudo isso que aconteceu.

A partir daquele momento, os pais proibiram que se falasse nessa profecia dentro de casa. Todos sabiam mas, se algum dia viessem a dizer a Janino seriam severamente castigados. Essa profecia foi relembrada por todos, no momento em que tomaram conhecimento do homicídio praticado por Janino. Segundo a irmã, nada poderia ter sido feito para evitar o crime. Referindo-se ao seu estado civil, Janino diz ser casado e solteiro ao mesmo tempo. Diz também, que se fizer sexo com uma mulher casada e o marido deixar e ela quiser, fica moça de novo. Isso pode também acontecer com mulher da vida.

... agora, do jeito que eu tou aqui com esse couro, é um atrapalho, até fazer sexo com uma mulher, porque não tou completo. Mas vou dar um jeito ainda. Vou ficar completo. Uma pessoa alva é mais completa. Agora, se eu passar esse meu poder de fazer virgem para alguém, o mundo vira um cabaré. E eu não tou louco para fazer isso. Tem um homem na fazenda querendo que eu passe esse poder para ele e como eu não posso passar, não vou lá, porque ele me expulsa.

Diz que, mesmo pequeno, com sete, oito anos, tinha dias que acordava pela manhã com vontade de matar um homem. Aí dizia isso à mãe e ela perguntava se ele tava doido. Refere que a sua mais antiga e marcante lembrança foi quando viu uma criança sendo raspada de faca para tirar o couro preto que tinha. Refere ainda um crime anterior, que não consta no prontuário, onde aos 12 anos teria matado dois irmãos, porque eles diziam que se deve matar os negros das famílias para poder limpá-las, porque só o alvo é completo. Acredita que só querem dar a ele o alvará quando ele se transformar. Mas, ele acha que na hora em que for assinar o alvará é que se transforma. O juiz já teria pedido para que ele casasse com a filha dele. Acredita que se fizesse isso, seria solto. No entanto, diz: 
não faço isso. Não quero ser melhor do que ela, que é até mulher branca, bonita. Mas, eu tenho na minha cabeça que não devo e aí eu não faço de jeito nenhum.

Indagado sobre o seu nome ou o nome de família, respondia que "era o dono do mundo; o rei do cangaço".

Para concluir, gostaríamos de apontar um dos possíveis ângulos de compreensão interpretativa que esse recorte de vida parece permitir, enfocando, mais explicitamente, o tema da violência, a partir dos seguintes operadores: linguagem, lei e desejo.

Destacaremos, de início, alguns pontos que pareceram relevantes em função do nosso objetivo aqui. Nesse sentido, admitimos que a relação de Janino com a linguagem apontaria para o que fora dito acima sobre o lugar que a palavra ocuparia enquanto significante do desejo.

Dissemos, há pouco, ser a linguagem a marca diferencial do humano. Dissemos, ainda, que somente através da palavra poderia o homem livrar-se do imediatismo determinista que caracterizaria os demais seres vivos. E que o desejo, por suas implicações com a fantasia, diferiria da necessidade, no sentido de poder, através de certos mecanismos, ser transformado em favor da construção de laços afetivos calcados em ideais, dentre outros, aqueles ideais de justiça e de solidariedade. Portanto, uma questão nuclear se colocaria, como direção no nosso caminho de escuta do dado empírico, a qual poderia ser formulada nos seguintes termos:

Por que, em Janino, a condição de sujeito falante, portanto, sujeito de linguagem/de desejo/de inconsciente, não fora suficiente para que pudesse ele sublimar a violência da exclusão de que fora alvo, ao invés de expressá-la, como o fizera, através de atos brutais de violência? Em outras palavras: por que a função simbólica não teria barrado a força desmedida do desejo evitando, portanto, em Janino, a passagem ao ato?

É de se indagar ainda, como corolário da questão nuclear se: o discurso do outro não o teria impedido de, através do simbólico, interditar seu desejo de onipotência, transformando, assim, tal discurso (do outro) em seu próprio discurso?

Em decorrência pode-se, também, interrogar: que significantes teriam capturado Janino, no discurso dos outros, isto é, no discurso daquelas pessoas que sobre ele falaram? 
Perseguindo uma cadeia de significantes, produzida nos vários discursos que dizem respeito a Janino, em torno do elemento sangue, destacaremos: a irmã que alude às lágrimas de sangue, que a mãe iria chorar, segundo a profecia de um sábio velho; o tal sábio velho que lhe profetiza um destino sangrento; a mãe que o repreende, severamente, quando ele the indaga sobre panos sujos de sangue; a criança que sangraria quando em processo de transformação do próprio corpo; a insistência do seu próprio desejo de, pela prática do homicídio, fazer sangrar outros (pai, mãe, irmãos, homens em geral); os saltos que teria dado sobre a vítima enquanto esta sangrava etc.

Ao que parece, Janino teria sido capturado/preso pela profecia do significante sangue, portanto, pelo discurso do outro. Desse modo, a palavra não teria sido eficaz, isto é, seu poder não teria sido suficiente para interditar, com êxito, a onipotência do desejo. Esse desejo, ao contrário, teria se desmembrado, de um lado, num processo destrutivo do próprio Janino e, de outro, na ânsia vã de uma busca desmedida de completude que o transcenderia. Não teria sido, assim, em Janino, realizada, com êxito, a função interditora da palavra. A lei não lhe teria aberto as portas para um mundo de sociabilidade, dominado pelos ideais. Reforçando, diríamos que, de algum modo, Janino teria sido capturado/tomado pela palavra, mas não teria podido se beneficiar da função interditora, da função de lei própria a essa palavra. Ficara ele, portanto, excluído do ideal de sociabilidade, numa constante postura de desafio e de transgressão. E assim, enfrentando a vida com uma identidade frouxa, Janino estaria desarmado para os embates com o enigma da relação com o outro, com o sexo e com o amor. Mergulhado em intenso tormento, teria buscado, na passagem ao ato, um certo prazer pelo alívio da sua insuportável tensão. Eliminando a sua vítima, desejaria, por certo, eliminar, também, o mal que o consumia. Mas, como o seu delito não teria podido aliviar as suas angústias e respondido às suas indagações - especialmente aquelas alusivas à falha do pai simbólico, enquanto não lhe garantira a barra da castração - Janino teria buscado, como novo recurso, o obscuro espaço de intensas alucinações, pelo poder que essas teriam de desligá-lo da realidade. Para Lacan, a alucinação seria fruto de uma representação psíquica que, irrompendo do lado de fora, se imporia como uma percepção. Seria uma resposta a 
um estado doloroso de desejo. Em outras palavras, seria o aparecimento, no real, daquilo que viera no simbólico, porém sem que esse pudesse exercer o seu poder de barra. E esse elemento fundamental que não teria podido ser por Janino simbolizado, isto é, a falta/castração/impotência, seria, de acordo com pensamento lacaniano, o que fora designado como real. E assim, enquanto inatingível, inominável o real equivaleria, também, ao gozo - sempre buscado porém, de todo, inalcançável.

\section{Questões QUE INSISTEM}

Tomando a violência pelo ângulo lacaniano da linguagem, que aspectos, no contexto sócio-histórico de Janino, poderiam haver produzido esse impedimento à função interditora da palavra, contribuindo para fortalecer esse destino, vaticinado pelos laços afetivos?

Valeria, talvez, repetir que o ponto central para uma visão da violência, à luz da teoria lacaniana, resultaria de uma falha na função da palavra. Dito de outro modo, seria uma falha na função simbólica, em relação ao seu estatuto de interdito, de lei constitutiva do sujeito. Tal falha consistiria, pois, num obstáculo à entrada do indivíduo no campo dos ideais, da ética, da solidariedade etc., entrada essa que marcaria o mundo humano, apesar dos descaminhos que venham a predominar em certos contextos históricos. Insistindo mais ainda, diríamos que a mencionada falha, na função da palavra, reforçaria a ilusão ou o desejo de onipotência, dificultando a interdição desse desejo, o que, por sua vez, poderia encontrar um elemento fortalecedor nas condições materiais de extrema carência, privação e precariedade, como bem o mostra o caso de Janino. Na nossa sociedade, nos últimos tempos, é freqüente a indagação: por que tanta violência, também, entre aqueles que não estão expostos a privações materiais?

$\mathrm{Na}$ perspectiva lacaniana, que referenciou as reflexões aqui formuladas, diríamos que, se por um lado, admitimos que a precariedade das condições materiais pode participar, fortemente, na produção da violência, por outro lado, é nosso objetivo apontar para o papel da força simbólica, interditora, que teria a palavra no que concerne à violência. Em outros termos, o que estaríamos reafirmando, aqui, seria o lugar da função 
simbólica somente realizada no espaço das relações afetivas, espaço esse que pressuporia as circunstâncias sócio-históricas.

Para finalizar, insistiremos, dizendo que, no nosso entendimento, a palavra não estaria nunca descolada dos vários elementos contextuais que cercam o humano - dentre eles as mencionadas condições materiais - no que diz respeito às conseqüências do desejo, em seu caráter de transgressão, no campo social.

Não parece demais insistirmos ainda, com base na leitura que fizemos de Lacan, que, em Janino, a metáfora paterna/função simbólica - afetada pela miséria material - teria incidido como realização fracassada do significante, no domínio simbólico. Tal domínio teria sido, portanto, insuficiente/ineficaz para barrar o seu desejo de destruição dirigido a ele próprio no campo do outro.

Como resíduo que desafia e instiga, ocorre-nos mais uma questão: será que, nesse cruzamento da metáfora paterna com a exclusão, não residiria um ponto de estilhaçamento, nada mais que um impasse o qual a psicanálise, inevitavelmente, teria que reconhecer e com ele se confrontar? E assim, não seria esse um enigma, um limite que desafiaria a psicanálise a uma escuta, cada vez mais singular, pressionada pelos emblemáticos conflitos sempre entrelaçados às contingências de cada história?

\section{REFERÊNCIAS BIBLIOGRÁFICAS}

Souza, A. A. A metáfora paterna. In: D. Checchinato (org.) Clínica da psicose. Campinas, SP: Ed. Papirus, 1988.

Dor, J. O pai e sua função em psicanálise. Rio de Janeiro: Ed. Jorge Zahar, 1991. Safouan, M. A palavra ou a morte. Campinas, SP: Ed. Papirus, 1993.

Guerra, A. G. O crime, realidade e desafio. Petrópolis: Ed. Vozes, 1990. —. Violência, afetividade e racismo. Céfiso, 13:136-150, 1998.

Henry, P. A ferramenta imperfeita: língua, sujeito e discurso. Campinas, SP: Ed. da Unicamp, 1992. 